\title{
Molecular screening strategies for NF1-like syndromes with café-au-lait macules (Review)
}

\author{
JIA ZHANG, MING LI and ZHIRONG YAO
}

\begin{abstract}
Department of Dermatology, Xinhua Hospital Affiliated to Shanghai Jiaotong University School of Medicine, Shanghai 200092, P.R. China
\end{abstract}

Received July 3, 2015; Accepted April 26, 2016

DOI: $10.3892 / \mathrm{mmr} .2016 .5760$

\begin{abstract}
Multiple café-au-lait macules (CALM) are usually associated with neurofibromatosis type 1 (NF1), one of the most common hereditary disorders. However, a group of genetic disorders presenting with CALM have mutations that are involved in human skin pigmentation regulation signaling pathways, including KIT ligand/KIT proto-oncogene receptor tyrosine kinase and Ras/mitogen-activated protein kinase. These disorders, which include Legius syndrome, Noonan syndrome with multiple lentigines or LEOPARD syndrome, and familial progressive hyperpigmentation) are difficult to distinguish from NF1 at early stages, using skin appearance alone. Furthermore, certain syndromes are clinically overlapping and molecular testing is a vital diagnostic method. The present review aims to provide an overview of these 'NF1-like' inherited diseases and recommend a cost-effective strategy for making a clear diagnosis among these diseases with an ambiguous borderline.
\end{abstract}

\section{Contents}

1. Introduction

2. The RASopathies with CALM

3. KITLG/KIT signaling pathway-associated genetic disorders with CALM

4. Conclusion

Correspondence to: Professor Zhirong Yao or Dr Ming Li, Department of Dermatology, Xinhua Hospital Affiliated to Shanghai Jiaotong University School of Medicine, 1665 Kongjiang Road, Shanghai 200092, P.R China

E-mail: zryaosmu@sohu.com

E-mail: aypyslm@163.com

Key words: café-au-lait macules, neurofibromatosis type 1, KITLG/c-Kit, Ras/MAPK, gene screening

\section{Introduction}

Neurofibromatosis type 1 (NF1; OMIM 162200) is one of the most common hereditary disorders. It is predominantly characterized by multiple café-au-lait macules (CALM), skin-fold freckling, Lisch nodules and neurofibromas. However, as the condition exhibits age-dependent characteristics and there are a number of other overlapping syndromes and similar diseases, it is usually difficult to make an early clinical diagnosis. Currently, although there are numerous comprehensive detection methods available for molecular diagnosis of NF1, the highest sensitivity of any of these methods is $\sim 95 \%(1,2)$. In addition to the limitations of detection by these approaches, cases of mosaic NF1 have been reported and there may exist other known or undefined genetic conditions with similar phenotypes. KIT ligand (KITLG) and its receptor KIT proto-oncogene receptor tyrosine kinase (KIT) activate the Ras/mitogen-activated protein kinase (MAPK) signaling pathway and they are critical in the control of physiological and pathological cutaneous pigmentation, including CALM (3). Known disorders with CALM comprise: i) A group of genetic syndromes resulting from germline mutations in genes that encode components or regulators of the Ras/MAPK signaling pathway, designated RASopathies, which consists of Noonan syndrome (NS; OMIM 163950), Legius syndrome [formerly termed NF1-like syndrome (NFLS); OMIM 611431], LEOPARD syndrome (LS; OMIM 151100), Costello syndrome (CS; OMIM 218040) and cardiofaciocutaneous syndrome (CFC; OMIM 115150), ii) disorders involving the KITLG/KIT signaling pathway, including piebaldism (OMIM 172800) and familial progressive hyperpigmentation (FPH; OMIM 145250). Although there are unique phenotypic characteristics for these conditions, certain syndromes remain highly overlapping and the differential diagnosis between them and NF1 is complex.

Our group recently conducted a large molecular research investigation into NF1 in a Chinese population (4-6). Patients without NF1 mutations who exhibited CALM were observed, and in a further study, other syndromes were demonstrated, including an atypical LS patient with a PTPNII mutation, a piebaldism patient with a KIT mutation and a familial progressive hyper- and hypopigmentation $(\mathrm{FPHH})$ patient with a KITLG mutation.

The present review discusses these KITLG/c-Kit- and Ras/MAPK signaling pathway-associated 'NF1-like' inherited 
Table I. 'NF1-like' genetic disorders with CALM involved in KITLG/c-Kit and Ras/MAPK signaling pathways.

\begin{tabular}{|c|c|c|c|c|}
\hline $\begin{array}{l}\text { Genetic } \\
\text { disorder }\end{array}$ & $\begin{array}{l}\text { Known causal } \\
\text { genes (proportion) }\end{array}$ & $\begin{array}{l}\text { Disease } \\
\text { identity }\end{array}$ & $\begin{array}{l}\text { Gene } \\
\text { identity }\end{array}$ & Characteristic features \\
\hline \multirow[t]{10}{*}{ NS } & PTPN11 (50\%) & \multirow[t]{9}{*}{ NS } & PTPN11 & \multirow{9}{*}{$\begin{array}{l}\text { CALM (10\%). Dysmorphic craniofacial features, cardiac } \\
\text { defect (pulmonary valve stenosis, hypertrophic } \\
\text { cardiomyopathy), musculoskeletal abnormalities, mental } \\
\text { retardation, cryptorchidism, hematologic malignancies }\end{array}$} \\
\hline & SOS1 $(10-15 \%)$ & & SOS1 & \\
\hline & RAF1 (5\%) & & RAF1 & \\
\hline & RIT1 $(5 \%)$ & & RIT1 & \\
\hline & KRAS $(<2 \%)$ & & NRAS & \\
\hline & BRAF (rare) & & SHOC2 & \\
\hline & NRAS (rare) & & CBL & \\
\hline & SHOC2 (rare) & & & \\
\hline & CBL (rare) & & & \\
\hline & & $\begin{array}{l}K R A S \text {-associated } \\
\text { NS-CFC-CS } \\
\text { spectrum }\end{array}$ & KRAS & $\begin{array}{l}\text { Less prominent ectodermal phenotypes; multiple nevi or } \\
\text { lentigines were rare or absent }\end{array}$ \\
\hline \multirow[t]{3}{*}{$\mathrm{CFC}$} & BRAF $(50-70 \%)$ & \multirow[t]{3}{*}{$\mathrm{CFC}$} & BRAF & CALM (9-31\%). Similar to NS. Ectodermal abnormalities such \\
\hline & MAP2K1/2 (25\%) & & MAP2K1/2 & as multiple nevi, keratosis pilaris, ulerythema ophryogenes and \\
\hline & KRAS $(<2 \%)$ & & & brittle, sparse, curly hair. Potential cancer risk \\
\hline \multirow[t]{3}{*}{ CS } & HRAS (>90\%) & \multirow[t]{7}{*}{$\mathrm{CS}$} & HRAS & \multirow{3}{*}{$\begin{array}{l}\text { CALM (rare). Similar to NS. Ectodermal abnormalities like } \\
\text { soft skin, deep palmar/plantar creases, papillomas and curly } \\
\text { hair. Severe failure to thrive. Significant cancer risk }(17 \%)\end{array}$} \\
\hline & BRAF (rare) & & & \\
\hline & KRAS (rare) & & & \\
\hline \multirow[t]{4}{*}{$\mathrm{LS}$} & PTPN11 (85\%) & & & \multirow{4}{*}{$\begin{array}{l}\text { CALM ( } 70-80 \%) \text {. Similar to NS, but with multiple lentigines } \\
\text { mostly on face, neck and upper part of the trunk. Unclear } \\
\text { cancer risk }\end{array}$} \\
\hline & RAF1 (rare) & & & \\
\hline & BRAF (rare) & & & \\
\hline & MAP2K1 (1 case) & & & \\
\hline NFLS & SPRED1 & & & Multiple CALM (nearly 100\%), intertriginous freckling. \\
\hline & & & & Potential risk of pediatric AML \\
\hline Piebaldism & KIT & & & Depigmented patches of skin and hair \\
\hline $\begin{array}{l}\text { FPH and } \\
\text { FPHH }\end{array}$ & KITLG & FPHH & KITLG & $\begin{array}{l}\text { Diffuse, partly blotchy hyperpigmented lesions intermingled } \\
\text { with scattered hypopigmentations, lentigines and CALM }\end{array}$ \\
\hline \multicolumn{5}{|c|}{$\begin{array}{l}\text { NF1, neurofibromatosis type 1; CALM, café-au-lait macules; KITLG, KIT ligand; c-Kit, KIT proto-oncogene receptor tyrosine kinase; } \\
\text { MAPK, mitogen-activated protein kinase; NS, Noonan syndrome; CFC, cardiofaciocutaneous syndrome; CS, Costello syndrome; LS, LEOP- } \\
\text { ARD syndrome; NFLS, NF1-like syndrome, Legius syndrome; FPH, familial progressive hyperpigmentation; FPHH, familial progressive } \\
\text { hyper- and hypopigmentation; HRAS, Harvey rat sarcoma viral oncogene homolog; KRAS, Kirsten rat sarcoma viral oncogene homolog; } \\
\text { PTPN11, protein tyrosine phosphatase, non-receptor type 11; SOS1, son of severnless homolog 1; RAF1, Raf-1 proto-oncogene serine/threo- } \\
\text { nine protein kinase; RIT1, Ras-like without CAAX 1; BRAF, B-Raf proto-oncogene, serine/threonine kinase; NRAS, neuroblastoma RAS vi- } \\
\text { ral oncogene homolog; SHOC2, SHOC2 leucine-rich repeat scaffold protein; CBL, Cbl proto-oncogene, E3 ubiquitin protein ligase; MAP2K, } \\
\text { MAPK kinase; SPRED1, sprouty related, EVH1 domain containing 1. }\end{array}$} \\
\hline
\end{tabular}

diseases, and proposes a molecular screening strategy to aid the determination of a definitive diagnosis.

\section{The RASopathies with CALM}

NFLS. NFLS presents predominantly with CALM, intertriginous freckling and certain less common manifestations ( 20\%), including neurocognitive impairment, developmental delay and macrocephaly, usually without neurofibromas, Lisch nodules, optic pathway glioma and other tumors $(7,8)$. More than $60 \%$ of the patients have a family history of the condition (9). These features meet three of the National Institutes of Health (NIH) diagnostic criteria for NF1 (10), thus, it is not reliable to distinguish NF1 from NFLS relying solely on clinical examination. Germline loss-of-function sprouty related, EVH1 domain containing 1 (SPRED1) mutations are responsible for this syndrome, which is most similar to NF1 in early childhood (11). It is estimated that $\sim 1-4 \%$ of individuals with multiple CALM harbor heterozygous SPRED1 mutations $(7,9)$. In subjects with familial CALM, with or without freckling and no other NF1 features, 73\% and $19 \%$ carry pathogenic NF1 mutations or SPRED1 mutations, respectively (7), which further indicates that genetic testing is useful in diagnosis in these cases (92\%). SPRED1 is involved in regulation of the MAPK signaling pathway, previous studies have demonstrated a loss of heterozygosity in pediatric acute myeloblastic leukemia, acting as a tumor suppressor $(12,13)$, this also indicates that this syndrome increases the risk of 


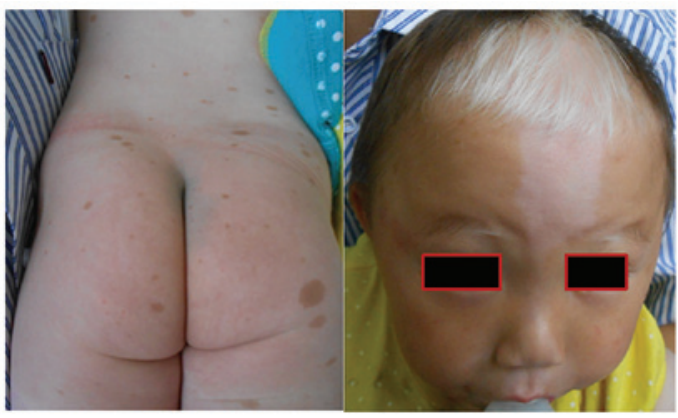

Figure 1. Clinical appearance of a piebaldism patient with a KIT proto-oncogene receptor tyrosine kinase mutation.

developing specific hematological malignancies, as well as other rare conditions, including kidney and lung cancer (8).

$L S$. LS is an autosomal dominant RASopathy, predominantly caused by mutations in protein tyrosine phosphatase, non-receptor type 11 (PTPN11; 85\%), in addition to less common genes, Raf-1 proto-oncogene, serine/threonine kinase (RAF1) and B-raf proto-oncogene, serine/threonine kinase $(B R A F)(10 \%)$. Individuals present with characteristic multiple lentigines, and relatively common features of RASopathies, including facial dysmorphia, myocardial and valvular abnormalities, and hearing loss. It is hard to clinically distinguish LS from other RASopathies, such as NF1 and NS, while molecular diagnosis is relatively reliable.

Twelve different missense PTPN11 mutations (Tyr279Cys/Ser, Ala461Thr/Ser, Gly464Ala, Thr468Met/Pro, Arg498Leu/Trp, Gln506Pro and Gln510Glu/Pro) (14-18) were reported to result in LS. Two of these mutations (Tyr279Cys and Thr468Met) account for $\sim 65 \%$ of the cases. Notably, these mutations cluster in the catalytic protein tyrosine phosphatase domain (amino acid residues, 221-524) (19), as in the allelic disorder, NS, the majority of missense mutations, small deletions and indels $(20,21)$ are associated with the $\mathrm{N}-\mathrm{SH} 2$ domain (amino acid residues, 3-104) (14). Contrary to the gain-of-function changes resulting in excessive PTPN11 activity in NS (12), LS mutants are catalytically defective and exert a dominant negative effect (22), suggesting that mutation type and region are important in the underlying pathogenic mechanisms and differential diagnoses of NS and LS. A recent study has suggested that LS-associated mutations may increase melanin synthesis in melanocytes via the activation of Akt/mammalian target of rapamycin signaling, thus, resulting in a phenotype with multiple lentigines (23).

Furthermore, a recent study identified a novel heterozygous MAPK kinase 1 (MAP2K1) mutation in LS, Glu102Gly (24), this is notable as mutations in this gene are usually associated with CFC. LS shares numerous phenotypic traits with CFC. Including this case, at present, germline mutations in $M A P 2 K 1$ and $B R A F$ genes are associated with CFC and LS. CALM and multiple nevi or lentigines are rare or absent in CFC patients with Kirsten rat sarcoma viral oncogene homolog $(K R A S)$ mutations (25), further demonstrating the complicated genetic heterogeneity and prominent overlapping feature of RASopathies.

CALM precede or are associated with lentigines in $10 \%$ of NS cases (26), and in up to $75 \%$ of LS cases (27), furthermore,

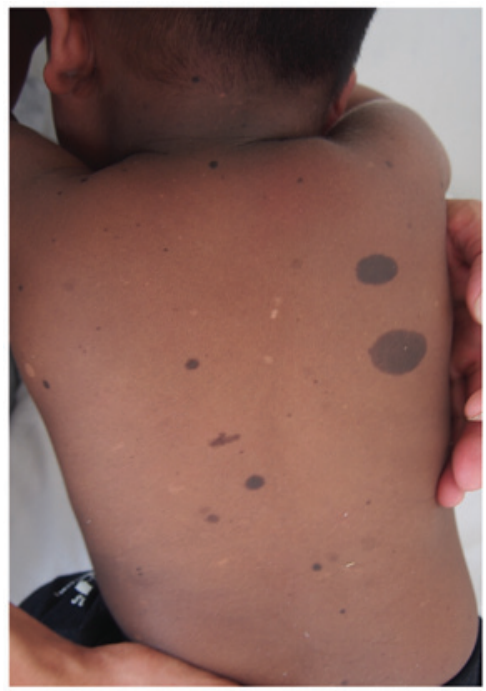

Figure 2. Clinical appearance of a familial progressive hyper- and hypopigmentation patient with a KIT ligand mutation.

in LS cases, the number of CALM can fulfills NIH criteria for diagnosis with NF1 (28). Lentigines usually appear during childhood as black-brown macules, predominantly on the face, neck and upper part of the trunk, and gradually increase in number and darken in color with age. Although LS patients have unclear disposition to malignancies, certain studies have reported an association with hematologic malignancies (29) and medulloblastoma (30), which should be noted.

$N S$-CFC-CS spectrum. NS shares numerous congenital anomalies with LS, excluding multiple lentigines. CFC and $\mathrm{CS}$ also have various clinical similarities and few differences compared with NS (25). Previously, clinical discrimination between these three syndromes was predominantly based on respective characteristic features, including hyperkeratotic skin, ichthyosis and keratosis pilaris in CFC patients; and soft and loose skin, deep palmar/plantar creases, nasal papillomas and an increased risk of developing malignancies in those with CS $(31,32)$. However, as the reported cases of RASopathies increase, these distinct features have also become highly overlapped.

Previous studies have demonstrated that one or two CALM are observed in 9-31\% of individuals in NS-CFC-CS spectrum disorders, this is markedly higher than the overall prevalence of $2.5 \%$ in neonates (33), while multiple CALM and intertriginous freckling were rare or absent $(25,26,34)$. In combination with the less common dysmorphic craniofacial features in $\mathrm{NF} 1$, the discrimination between these conditions and NF1 is relatively easier.

KRAS mutations associated with the NS-CFC-CS spectrum predominantly confer mild gain-of-function effect (35). The present review suggests that KRAS mutations associated with the NS-CFC-CS spectrum belong to an identical entity relatively close to NS (see Table I, which provides a proper hypothesis for a new classification of these RASopathies and corresponding causal genes) as: i) CFC, NS and CS exhibit numerous clinical similarities and few differences $(25,36,37)$; ii) KRAS mutations have been reported in $<2 \%$ of the NS and CFC cases (37), as well as in only a handful of CS 


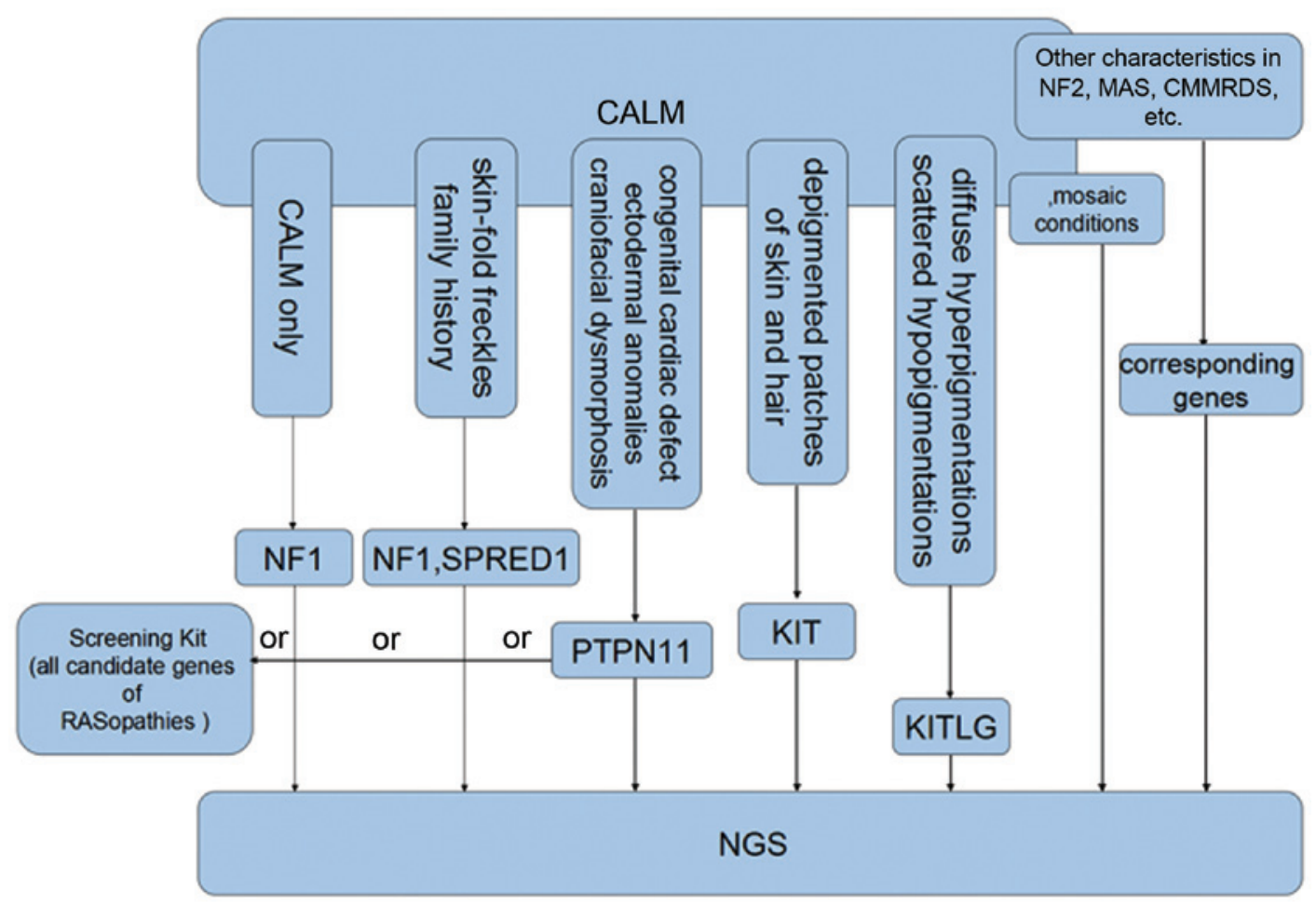

Figure 3. Screening strategies for inherited disorders with CALM that clinically resemble NF1, particularly those involved in KITLG/KIT and Ras/mitogen-activated protein kinase signaling pathways. CALM, café-au-lait macules; NF1, neurofibromatosis type 1; KIT, KIT proto-oncogene receptor tyrosine kinase; KITLG, KIT ligand; SPRED1, sprouty related, EVH1 domain containing 1; PTPN11, protein tyrosine phosphatase, non-receptor type 11; NF2, neurofibromatosis type 2; MAS. McCune-Albright syndrome; CMMRDS, constitutional mismatch repair deficiency; NGS, next generation sequencing.

patients $(35,38)$, and all three of the independent conditions demonstrated their major pathogenic form, PTPN11, BRAF and $H R A S$, respectively (presented in Table I); iii) mutations Asp153Val, Thr58Ile and other missense mutations in the same amino acid residue in $K R A S$ were reported to result in NS and CFC $(25,39,40)$; iv) less prominent ectodermal phenotypes were observed in CFC and CS with KRAS mutations than those with $B R A F$ mutations $(25,34,39,41)$; v) multiple nevi or lentigines were rare or absent in CFC patients with $K R A S$ mutations compared with those with mutations in $M A P 2 K 1$ and BRAF (25).

In the majority of instances, $B R A F$ mutations resulting in NS have not been observed in CFC, suggesting the associated phenotypes may be allele specific (42), however, a number of $B R A F$ mutations, including Ala246Pro and Gln257Arg, have been demonstrated in the two conditions (25).

Previous studies have also demonstrated the evolution of the clinical phenotype in a CFC patient, and the marked resemblance between CFC and NS, consistent with the suggestion that NS and CFC are variable manifestations of the same entity $(36,43)$.

Taking updated molecular findings, reviews of complex genetic heterogeneity and the highly overlapping features of these disorders into consideration, the present review hypothesizes these three disorders may be not distinct and separate conditions, but a continuous spectrum consisting of a certain gene or group of gene-related subtypes with certain degrees of phenotypic variability, particularly $K R A S$-associated NS-CFC-CS spectrum (as presented in Table I), or multiple alternative underlying mechanisms are involved in the functional dysregulation of the Ras/MAPK signaling pathway.

Allelic syndromes of NF1: Neurofibromatosis-Noonan syndrome and Watson syndrome. The disorder designated neurofibromatosis-Noonan syndrome (NFNS; OMIM 601321) is a variant of NF1 rather than NS, predominantly due to mutations in the NF1 gene (44). It may fulfill the criteria for NF1 with CALM and skin-fold freckling, but also has overlapping features with NS, including 'Noonan' face, short stature, congenital heart defects and a predisposition to malignancy.

Watson syndrome (WS; OMIM 193520) is characterized by pulmonic stenosis, CALM and intellectual impairment (45), furthermore, Lisch nodules are observed in the majority of affected subjects, and neurofibromas in 1/3 (46). An 80-kb deletion and an in-frame tandem duplication of 42 bases at the NF1 locus have been reported in patients with WS $(47,48)$. These findings broaden the noteworthy NF1-associated phenotype spectrum and are consistent with NFNS and WS as allelic disorders or subtypes of NF1. An alternative explanation is that they are the result of an additive effect of mutations in NF1 and other relevant genes, including PTPN11 or unknown modifying loci $(49,50)$.

\section{KITLG/KIT signaling pathway-associated genetic dis- orders with CALM}

Piebaldism. Piebaldism is a rare autosomal dominant disorder caused by KIT mutations. Characteristic features are depigmented patches of skin and hair (as presented in Fig. 1). Of 
the three reported piebaldism cases with multiple CALM and intertriginous freckling, all the mutations were located in the tyrosine kinase (TK) domain (Gly610Asp, Gliu640Asp and Arg791Gly) (51-53). It has been demonstrated that inadequate phosphorylation of the KIT-binding domain in SPRED1 due to a defective KIT TK would result in loss of inhibition of the Ras/MAPK signaling pathway, leading to a phenotype similar to NFLS (53), while gain-of function mutations in KITLG have been reported to result in FPHH (54), indicating KIT and KITLG are important modulators of skin pigmentation.

Phenotypic severity depends on the type and site of the mutation $(55,56)$. Mutations in the TK region (TK1, 582-684 and TK2, 762-973) exert a dominant-negative effect, usually resulting in a severe phenotype, whereas mild cases are frequently due to mutations in the extracellular region.

Patients with piebaldism may develop CALM (as presented in Fig. 1), NF1 may be associated with piebaldism, and these two distinct conditions may co-exist in one patient $(57,58)$, which highlights the necessity of molecular diagnosis.

FPHH and FPH. FPHH is notable for progressive, diffuse, partly blotchy hyperpigmented lesions intermingled with scattered hypopigmented spots, lentigines and CALM (as presented in Fig. 2) (6). It is the result of a mutation in $K I T L G$, encoding KITLG involved in the Ras/MAPK signaling pathway (54). Clinical signs are somewhat different from its allelic disorder FPH (59), in which no hypopigmentation is present. Notably, the mutation p.Asn36Ser results in FPH and FPHH, with the FPH patient image in a previous study by Wang et al (59) also demonstrating small suspicious hypopigmented lesions (54). This suggests these two disorders may resemble another pigmentary genetic disorder termed Dowling-Degos disease (DDD; OMIM 179850, 615327 and 615696) (60-63), which may also be the same condition with a degree of phenotypic variability, for example, in the distribution of hyperpigmented and hypopigmented lesions.

\section{Conclusion}

The RASopathies have complex genetic heterogeneity and marked overlapping features, however, a relatively correct diagnosis is essential for genetic counseling regarding prognosis (as the diagnosis of milder phenotypes, including NFLS or mosaic NF1, may relieve the psychological burden on serious age-dependent complications); monitoring of potential risks, including cancer and cardiac events; and prevention using prenatal diagnosis.

Thus, the current review proposes a screening strategy in which: i) NF1 testing has a priority for patients that only exhibit CALM or fulfill the NIH diagnostic criteria for NF1; ii) SPRED1 and NF1 should be tested in those with skin-fold freckling and a family history; iii) in NF1-negative pediatric patients with CALM and a dispersed pattern of facial and cervical freckles, PTPN11 should be first considered for molecular analysis, as it accounts for the majority of LS and NS cases; iv) genetic testing of KITLG and KIT is used and relatively effective in those with diffuse hyperpigmented lesions intermingled with scattered depigmentation, depigmented patches of skin and hair, respectively (as presented in Fig. 3).
As for other RASopathies, BRAF and $H R A S$ analysis is suitable for relatively typical CFC and CS presentations, respectively. However, when considering the highly overlapping phenotypes and involvement of numerous genes, a custom-designed screening kit including all the candidate genes for the various RASopathies is a thorough alternative choice.

Furthermore, few patients with CALM fall outside the above mentioned disorders and their condition may be the result of mutations in other undetected genes associated with the Ras/MAPK signaling pathway, for instance, recently identified causal genes $\mathrm{Cbl}$ proto-oncogene $\mathrm{E} 3$ ubiquitin protein ligase and Ras-like without CAAX $1(64,65)$. Considering the detection limit of general sequencing methods, especially for those atypical or unreported phenotypes, next generation sequencing (such as whole exome sequencing and whole genome sequencing) still serves as a cost-effective approach for molecular diagnosis of the above disorders with CALS, as well as other possible genetic diseases, including neurofibromatosis type 2 (OMIM 101000) with vestibular schwannomas; McCune-Albright syndrome (OMIM 174800) with segmental CALM, polyostotic fibrous dysplasia and precocious puberty; constitutional mismatch repair deficiency syndrome (OMIM 276300) with childhood cancer predisposition (66); and various mosaic conditions associated with CALM (as presented in Fig. 3).

\section{Acknowledgements}

The current review was supported by a grant from the Ph.D. Programs Foundation of Ministry of Education of China (grant no. 20130073120014), a grant from the Natural Science Foundation of Shanghai Jiaotong University School of Medicine (grant no. 13XJ10023) and a grant from the Foundation of Xinhua Hospital Affiliated to Shanghai Jiaotong University School of Medicine (grant no. 15YJ15).

\section{References}

1. Messiaen LM, Callens T, Mortier G, Beysen D, Vandenbroucke I, Van Roy N, Speleman F and Paepe AD: Exhaustive mutation analysis of the NF1 gene allows identification of $95 \%$ of mutations and reveals a high frequency of unusual splicing defects. Hum Mutat 15: 541-555, 2000.

2. Valero MC,Martin Y,Hernández-ImazE, Marina Hernández A, Meleán G, Valero AM, Javier Rodríguez-Álvarez F, Tellería D and Hernández-Chico C: A highly sensitive genetic protocol to detect NF1 mutations. J Mol Diagn 13: 113-122, 2011.

3. Picardo $\mathrm{M}$ and Cardinali G: The genetic determination of skin pigmentation: KITLG and the KITLG/c-Kit pathway as key players in the onset of human familial pigmentary diseases. J Invest Dermatol 131: 1182-1185, 2011.

4. Zhang J, Tong H, Fu X, Zhang Y, Liu J, Cheng R, Liang J, Peng J, Sun Z, Liu H, et al: Molecular characterization of NF1 and neurofibromatosis type 1 genotype-phenotype correlations in a Chinese population. Sci Rep 5: 11291, 2015.

5. Zhang J, Cheng R, Liang J, Ni C, Li M and Yao Z: Lentiginous phenotypes caused by diverse pathogenic genes (SASH1 and PTPN11): Clinical and molecular discrimination. Clin Genet: Feb 3, 2016 (Epub ahead of print).

6. Zhang J, Cheng R, Liang J, Ni C, Li M and Yao Z: Report of a sporadic familial progressive hyper- and hypopigmentation child caused by a novel KITLG mutation. Br J Dermatol: Apr 23, 2016 (Epub ahead of print).

7. Messiaen L, Yao S, Brems H, Callens T, Sathienkijkanchai A, Denayer E, Spencer E, Arn P, Babovic-Vuksanovic D, Bay C, et al: Clinical and mutational spectrum of neurofibromatosis type 1-like syndrome. JAMA 302: 2111-2118, 2009. 
8. Brems H, Pasmant E, Van Minkelen R, Wimmer K, Upadhyaya M, Legius E and Messiaen L: Review and update of SPRED1 mutations causing Legius syndrome. Hum Mutat 33: 1538-1546, 2012.

9. Brems H and Legius E: Legius syndrome, an update. Molecular pathology of mutations in SPRED1. Keio J Med 62: 107-112, 2013.

10. [No authors 1sited]: Neurofibromatosis. Conference statement. National Institutes of Health Consensus Development Conference. Arch Neurol 45: 575-578, 1988.

11. Brems H, Chmara M, Sahbatou M, Denayer E, Taniguchi K, Kato R, Somers R, Messiaen L, De Schepper S, Fryns JP, et al: Germline loss-of-function mutations in SPRED1 cause a neurofibromatosis 1-like phenotype. Nat Genet 39: 1120-1126, 2007.

12. Pasmant E, Gilbert-Dussardier B, Petit A, de Laval B Luscan A, Gruber A, Lapillonne H, Deswarte C, Goussard P, Laurendeau I, et al: SPRED1, a RAS MAPK pathway inhibitor that causes Legius syndrome, is a tumour suppressor downregulated in paediatric acute myeloblastic leukaemia. Oncogene 34 631-638, 2015.

13. Pasmant E, Ballerini P, Lapillonne H, Perot C, Vidaud D, Leverger $G$ and Landman-Parker J: SPRED1 disorder and predisposition to leukemia in children. Blood 114: 1131, 2009.

14. Tartaglia M, Mehler EL, Goldberg R, Zampino G, Brunner HG Kremer H, van der Burgt I, Crosby AH, Ion A, Jeffery S, et al: Mutations in PTPN11, encoding the protein tyrosine phosphatase SHP-2, cause Noonan syndrome. Nat Genet 29 : 465-468, 2001

15. Conti E, Dottorini T, Sarkozy A, Tiller GE, Esposito G, Pizzuti A and Dallapiccola B: A novel PTPN11 mutation in LEOPARD syndrome. Hum Mutat 21: 654, 2003.

16. Martínez-Quintana E and Rodríguez-González F: LEOPARD Syndrome: Clinical features and gene mutations. Mol Syndromol 3: 145-157, 2012.

17. Wang Y, Chen C and Wang DW: Leopard syndrome caused by heterozygous missense mutation of Tyr 279 Cys in the PTPN11 gene in a sporadic case of Chinese Han. Int J Cardiol 174: e101-e104, 2014.

18. Osawa R, Akiyama M, Yamanaka Y, Ujiie H, Nemoto-Hasebe I, Takeda A, Yanagi T and Shimizu H: A novel PTPN11 missense mutation in a patient with LEOPARD syndrome. Brit J Dermatol 161: 1202-1204, 2009

19. Digilio MC, Conti E, Sarkozy A, Mingarelli R, Dottorini T, Marino B, Pizzuti A and Dallapiccola B: Grouping of multiple-lentigines/LEOPARD and Noonan syndromes on the PTPN11 gene. Am J Hum Genet 71: 389-394, 2002

20. Yoshida R, Hasegawa T, Hasegawa Y, Nagai T, Kinoshita E, Tanaka Y, Kanegane H, Ohyama K, Onishi T, Hanew K, et al: Protein-tyrosine phosphatase, nonreceptor type 11 mutation analysis and clinical assessment in 45 patients with Noonan syndrome. J Clin Endocrinol Metab 89: 3359-3364, 2004.

21. Tartaglia M, Martinelli S, Stella L, Bocchinfuso G, Flex E, Cordeddu V, Zampino G, Burgt Iv, Palleschi A, Petrucci TC et al: Diversity and functional consequences of germline and somatic PTPN11 mutations in human disease. Am J Hum Genet 78: 279-290, 2006

22. Kontaridis MI, Swanson KD, David FS, Barford D and Neel BG: PTPN11 (Shp2) mutations in LEOPARD syndrome have dominant negative, not activating, effects. J Biol Chem 281: 6785-6792, 2006.

23. Motegi S, Yokoyama Y, Ogino S, Yamada K, Uchiyama A Perera B, Takeuchi Y, Ohnishi $\mathrm{H}$ and Ishikawa O: Pathogenesis of multiple lentigines in LEOPARD syndrome with PTPN11 gene mutation. Acta Derm Venereol 95: 978-984, 2015.

24. Nishi E,Mizuno S, Nanjo Y,NiihoriT, Fukushima Y,Matsubara Y, Aoki Y and Kosho T: A novel heterozygous MAP2K1 mutation in a patient with Noonan syndrome with multiple lentigines. Am J Med Genet A 167A: 407-411, 2015

25. Nava C, Hanna N, Michot C, Pereira S, Pouvreau N, Niihori T, Aoki Y, Matsubara Y, Arveiler B, Lacombe D, et al: Cardio-facio-cutaneous and Noonan syndromes due to mutations in the RAS/MAPK signalling pathway: Genotype-phenotype relationships and overlap with Costello syndrome. J Med Genet 44: 763-771, 2007.

26. Allanson JE: Noonan syndrome. J Med Genet 24: 9-13, 1987.

27. Digilio MC, Sarkozy A, de Zorzi A, Pacileo G, Limongelli G, Mingarelli R, Calabrò R, Marino $B$ and Dallapiccola $B$ : LEOPARD syndrome: Clinical diagnosis in the first year of life. Am J Med Genet A 140: 740-746, 2006
28. Carcavilla A, Pinto I, Muñoz-Pacheco R, Barrio R, Martin-Frias M and Ezquieta B: LEOPARD syndrome (PTPN11, $\mathrm{T} 468 \mathrm{M}$ ) in three boys fulfilling neurofibromatosis type 1 clinical criteria. Eur J Pediatr 170: 1069-1074, 2011.

29. Tartaglia M, Niemeyer CM, Fragale A, Song X, Buechner J, Jung A, Hählen K, Hasle H, Licht JD and Gelb BD: Somatic mutations in PTPN11 in juvenile myelomonocytic leukemia, myelodysplastic syndromes and acute myeloid leukemia. Nat Genet 34: 148-150, 2003.

30. Rankin J, Short J, Turnpenny P, Castle B and Hanemann CO: Medulloblastoma in a patient with the PTPN11 p.Thr468Met mutation. Am J Med Genet A 161A: 2027-2029, 2013.

31. Hennekam RC: Costello syndrome: An overview. Am J Med Genet Part C Semin Med Genet 117C: 42-48, 2003.

32. Bryan ZT, Missall TA, Stieren S, Siegfried E and Burkemper NM: Clinicopathologic evaluation of cardiofaciocutaneous syndrome: Overcoming the challenges of diagnosing a rare genodermatosis Pediatr Dermatol 32: e23-e28, 2015

33. Alper J, Holmes LB and Mihm MC Jr: Birthmarks with serious medical significance: Nevocellular nevi, sebaceous nevi, and multiple café au lait spots. J Pediatr 95: 696-700, 1979.

34. SiegelDH,McKenzie J, Frieden IJ and Rauen KA: Dermatological findings in 61 mutation-positive individuals with cardiofaciocutaneous syndrome. Brit J Dermatol 164: 521-529, 2011.

35. Zenker M, Lehmann K, Schulz AL, Barth H, Hansmann D, Koenig R, Korinthenberg R, Kreiss-Nachtsheim M, Meinecke P, Morlot S, et al: Expansion of the genotypic and phenotypic spectrum in patients with KRAS germline mutations. J Med Genet 44: 131-135, 2007

36. Fryer AE, Holt PJ and Hughes HE: The cardio-facio-cutaneous (CFC) syndrome and Noonan syndrome: Are they the same? Am J Med Genet 38: 548-551, 1991.

37. Tidyman WE and Rauen KA: Noonan, Costello and cardio-facio-cutaneous syndromes: Dysregulation of the Ras-MAPK pathway. Expert Rev Mol Med 10: e37, 2008.

38. Bertola DR, Pereira AC, Brasil AS, Albano LM, Kim CA and Krieger JE: Further evidence of genetic heterogeneity in Costello syndrome: Involvement of the KRAS gene. J Hum Genet 52: 521-526, 2007.

39. Niihori T, Aoki Y, Narumi Y, Neri G, Cavé H, Verloes A, Okamoto N, Hennekam RC, Gillessen-Kaesbach G, Wieczorek D, et al: Germline KRAS and BRAF mutations in cardio-facio-cutaneous syndrome. Nat Genet 38: 294-296, 2006.

40. Schubbert S, Zenker M, Rowe SL, Böll S, Klein C, Bollag G, van der Burgt I, Musante L, Kalscheuer V, Wehner LE, et al: Germline KRAS mutations cause Noonan syndrome. Nat Genet 38: 331-336, 2006.

41. Abe $\mathrm{Y}$, Aoki $\mathrm{Y}$, Kuriyama S, Kawame H, Okamoto $\mathrm{N}$, Kurosawa K, Ohashi H, Mizuno S, Ogata T, Kure S, et al: Prevalence and clinical features of Costello syndrome and cardio-facio-cutaneous syndrome in Japan: Findings from a nationwide epidemiological survey. Am J Med Genet A 158A: 1083-1094, 2012

42. Sarkozy A, Carta C, Moretti S, Zampino G, Digilio MC, Pantaleoni F, Scioletti AP, Esposito G, Cordeddu V, Lepri F, et al: Germline BRAF mutations in Noonan, LEOPARD, and cardiofaciocutaneous syndromes: Molecular diversity and associated phenotypic spectrum. Hum Mutat 30: 695-702, 2009.

43. Neri G and Zollino M: More on the Noonan-CFC controversy. Am J Med Genet 65: 100, 1996.

44. De Luca A, Bottillo I, Sarkozy A, Carta C, Neri C, Bellacchio E, Schirinzi A, Conti E, Zampino G, Battaglia A, et al: NF1 gene mutations represent the major molecular event underlying neurofibromatosis-Noonan syndrome. Am J Hum Genet 77: 1092-1101, 2005

45. Watson GH: Pulmonary stenosis, café-au-lait spots, and dull intelligence. Arch Dis Child 42: 303-307, 1967.

46. Allanson JE, Upadhyaya M, Watson GH, Partington M, MacKenzie A, Lahey D, MacLeod H, Sarfarazi M, Broadhead W, Harper PS, et al: Watson syndrome: Is it a subtype of type 1 neurofibromatosis? J Med Genet 28: 752-756, 1991.

47. Upadhyaya M, Shen M, Cherryson A, Farnham J, Maynard J, Huson SM and Harper PS: Analysis of mutations at the neurofibromatosis 1 (NF1) locus. Hum Mol Genet 1: 735-740, 1992

48. Tassabehji M, Strachan T, Sharland M, Colley A, Donnai D, Harris R and Thakker N: Tandem duplication within a neurofibromatosis type 1 (NF1) gene exon in a family with features of Watson syndrome and Noonan syndrome. Am J Hum Genet 53: 90-95, 1993. 
49. Thiel C, Wilken M, Zenker M, Sticht H, Fahsold R, Gusek-Schneider GC and Rauch A: Independent NF1 and PTPN11 mutations in a family with neurofibromatosis-Noonan syndrome. Am J Med Genet A 149A: 1263-1267, 2009.

50. Nyström AM,Ekvall S, Strömberg B,Holmström G, Thuresson AC, Annerén G and Bondeson ML: A severe form of Noonan syndrome and autosomal dominant café-au-lait spots-evidence for different genetic origins. Acta Paediatr 98: 693-698, 2009.

51. Spritz RA, Itin PH and Gutmann DH: Piebaldism and neurofibromatosis type 1: Horses of very different colors. J Invest Dermatol 122: xxxiv-xxxv, 2004.

52. Duarte AF, Mota A, Baudrier T, Morais P, Santos A, Cerqueira R, Tavares $\mathrm{P}$ and Azevedo F: Piebaldism and neurofibromatosis type 1: Family report. Dermatol Online J 16: 11, 2010.

53. Chiu YE, Dugan S, Basel D and Siegel DH: Association of Piebaldism, multiple café-au-lait macules, and intertriginous freckling: Clinical evidence of a common pathway between KIT and sprouty-related, ena/vasodilator-stimulated phosphoprotein homology-1 domain containing protein 1 (SPRED1). Pediatr Dermatol 30: 379-382, 2013.

54. Amyere M, Vogt T, Hoo J, Brandrup F, Bygum A, Boon L and Vikkula M: KITLG mutations cause familial progressive hyperand hypopigmentation. J Invest Dermatol 131: 1234-1239, 2011.

55. Oiso N, Fukai K, Kawada A and Suzuki T: Piebaldism. J Dermatol 40: 330-335, 2013.

56. Spritz RA: Molecular basis of human piebaldism. J Invest Dermatol 103 (Suppl 5): S137-S140, 1994.

57. Angelo C, Cianchini G, Grosso MG, Zambruno G, Cavalieri R and Paradisi M: Association of piebaldism and neurofibromatosis type 1 in a girl. Pediatr Dermatol 18: 490-493, 2001.

58. Duarte A, Mota A, Baudrier T, Morais P, Santos A, Cerqueira R, Tavares P and Azevedo F: Piebaldism and neurofibromatosis: State of knowledge. Dermatol Online J 19: 17, 2013.
59. Wang ZQ, Si L, Tang Q, Lin D, Fu Z, Zhang J, Cui B, Zhu Y, Kong X, Deng M, et al: Gain-of-function mutation of KIT ligand on melanin synthesis causes familial progressive hyperpigmentation. Am J Hum Genet 84: 672-677, 2009.

60. Betz RC, Planko L, Eigelshoven S, Hanneken S, Pasternack SM, Bussow H, Van Den Bogaert K, Wenzel J, Braun-Falco M, Rutten A, et al: Loss-of-function mutations in the keratin 5 gene lead to Dowling-Degos disease. Am J Hum Genet 78: 510-519, 2006.

61. Pickup TL and Mutasim DF: Dowling-Degos disease presenting as hypopigmented macules. J Am Acad Dermatol 64: 1224-1225, 2011.

62. Li M, Cheng R, Liang J, Yan H, Zhang H, Yang L, Li C, Jiao Q, $\mathrm{Lu} \mathrm{Z}, \mathrm{He} \mathrm{J}$, et al: Mutations in POFUT1, encoding protein O-fucosyltransferase 1, cause generalized Dowling-Degos disease. Am J Hum Genet 92: 895-903, 2013.

63. Basmanav FB, Oprisoreanu AM, Pasternack SM, Thiele H, Fritz G, Wenzel J, Größer L, Wehner M, Wolf S, Fagerberg C, et al: Mutations in POGLUT1, encoding protein O-glucosyltransferase 1, cause autosomal-dominant Dowling-Degos disease. Am J Hum Genet 94: 135-143, 2014.

64. Pérez B, Mechinaud F, Galambrun C, Ben Romdhane N, Isidor B, Philip N, Derain-Court J, Cassinat B, Lachenaud J, Kaltenbach S, et al: Germline mutations of the CBL gene define a new genetic syndrome with predisposition to juvenile myelomonocytic leukaemia. J Med Genet 47: 686-691, 2010.

65. Aoki Y, Niihori T, Banjo T, Okamoto N, Mizuno S, Kurosawa K, Ogata T, Takada F, Yano M, Ando T, et al: Gain-of-function mutations in RIT1 cause Noonan syndrome, a RAS/MAPK pathway syndrome. Am J Hum Genet 93: 173-180, 2013.

66. Shah KN: The diagnostic and clinical significance of café-au-lait macules. Pediatr Clin North Am 57: 1131-1153, 2010 . 